\title{
SIMULATION OF THE RIDE FOR PASSENGER CAR IN NEDC AND WLTP DRIVING CYCLES
}

\author{
P. Brabec ${ }^{*}$, X. Zhou ${ }^{* *}$
}

\begin{abstract}
The paper deals with the current regulations on the reduction of passenger cars emissions. It describes a simulation model of a vehicle in Ricardo Ignite software, a comparison of fuel consumption (production $\mathrm{CO}_{2}$ ) of a conventional vehicle with an internal combustion engine in the "New European Driving Cycle" and "Worldwide Harmonized Light Vehicles Test Cycle" driving cycles. The goal was to create a vehicle simulation model and to verify it with measured data. In the future, this simulation model can be used for various optimizations which will reduce vehicle fuel consumption ( $\mathrm{CO}_{2}$ production) due to constantly more restrictive limits. At the end of the paper, there is a demonstration of a reduction of $\mathrm{CO}_{2}$ emissions when using the so-called downsizing.
\end{abstract}

Keywords: simulation, car, fuel consumption, $\mathrm{CO}_{2}$, NEDC, WLTC

\section{Introduction}

The development of the car and in particular the drive train has always been characterized in the past by the use of new technologies. The use of innovations is also being driven forward by legal requirements such as regulations on the emissions and the fuel consumption, the introduction and increasingly strict of emission limits. In recent years, one of the focal points of development work has been on compliance with the strict EU5 and EU6 exhaust limits. Today's automakers have their sights fixed on 2020 , and the $95 \mathrm{~g} / \mathrm{km} \mathrm{CO}_{2}$ proposal for passenger cars $(2015-130 \mathrm{~g} / \mathrm{km}, 2006-160 \mathrm{~g} / \mathrm{km}$ - reduction of $19 \%$ respectively $41 \%$ ). Figure 1 shows what we currently expect, both as concerns the status of legislation and the likely scenarios for enactment (Schöppe et al., 2013; Kirsten, 2011; Denner, 2013). The figure shows the change from the NEDC (New European Driving Cycle) to the new WLTC (Worldwide Harmonized Light Vehicles Test Cycle) driving cycle. The WLTP (Worldwide Harmonized Light vehicles Test Procedure) methodology or, more precisely, its laboratory component WLTC (WLTP is consisted of WLTC and RDE) is much more realistic than NEDC, but this does not mean that it is completely flawless. Despite the extension of the duration, it cannot be expected that the WLTC would include exceptional, but still emissions and fuel consumption affecting, driving modes. This is, for example, the case of the regeneration of a particulate filter, where most cars have increased fuel

\footnotetext{
* Ing. Pavel Brabec, Ph.D.: Technical University of Liberec, Studentská 2; 461 17, Liberec 1; CZ, pavel.brabec@tul.cz

** Xiaoxiao Zhou: University of Macau, Avenida da Universidade, Taipa, Macau; PRC, zhou_xiaoxiao@outlook.com
}

Fig. 1: The outline of current and future emissions and $\mathrm{CO}_{2}$ legislation in the EU (Denner, 2013). 
consumption and smokiness. Another question is how to assess hybrid vehicles that can use electric power for a considerable part of the cycle. The WLTC, compared to the NEDC, lasts longer and covers more than double distance. This is then reflected into cold-start emission effects being relatively lower. Furthermore, the WLTC has higher maximum, average and driving speeds, and almost half the idling period (although the single stop with the longest duration is $66 \mathrm{~s}$ for the WLTC and only 27 for the NEDC). For approximately $84 \%$ of the time during the WLTC the vehicle operates in transient conditions (accelerating or decelerating), in contrast to only $37 \%$ in the NEDC. Cruising time is almost absent in the WLTC. These are expected to result in higher engine-out pollutant emissions and higher $\mathrm{CO}_{2}$ (Evangelos, 2017).

Tab. 1: Technical specifications of the European NEDC and WLTC (Evangelos, 2017).

\begin{tabular}{lcccc}
\hline & NEDC & \multicolumn{3}{c}{ WLTC } \\
\hline Distance $(\mathrm{m}) /$ Duration $(\mathrm{s}$ or $\mathrm{min})$ & 11000 & $1180(19.67)$ & 23266.3 & $1800(30)$ \\
\hline Maximum/Average vehicle speed $(\mathrm{km} / \mathrm{h})$ & 120.00 & 33.56 & 131.30 & 46.53 \\
\hline Average/Maximum acceleration $\left(\mathrm{m} / \mathrm{s}^{2}\right)$ & 0.594 & 1.042 & 0.406 & 1.667 \\
\hline Average/Minimum deceleration $\left(\mathrm{m} / \mathrm{s}^{2}\right)$ & -0.789 & -1.389 & -0.445 & -1.5 \\
\hline Driving time $(\mathrm{s}) /(\%)$ & 900 & 76.27 & 1574 & 87.44 \\
\hline Driving time $(\%) \mathrm{V} \leq 30 \mathrm{~km} / \mathrm{h} / 30<\mathrm{V} \leq 60 \mathrm{~km} / \mathrm{h}$ & 46.44 & 33.81 & 40.22 & 27.94 \\
\hline Driving time $(\%) 60<\mathrm{V} \leq 100 \mathrm{~km} / \mathrm{h} / \mathrm{V}>100 \mathrm{~km} / \mathrm{h}$ & 16.61 & 3.14 & 21.72 & 10.11 \\
\hline Time spent accelerating $(\mathrm{s}) /(\%)$ & 247 & 20.93 & 789 & 43.83 \\
\hline Acceleration time $(\%) 0<\mathrm{a} \leq 1.0 \mathrm{~m} / \mathrm{s}^{2} / \mathrm{a}>1.0 \mathrm{~m} / \mathrm{s}^{2}$ & 19.58 & 1.35 & 39.83 & 4.00 \\
\hline Time spent decelerating $(\mathrm{s}) /(\%)$ & 186 & 15.76 & 719 & 39.94 \\
\hline Decel. time $(\%) \mathrm{a}<-1.0 \mathrm{~m} / \mathrm{s}^{2} /-1.0 \leq \mathrm{a}<0 \mathrm{~m} / \mathrm{s}^{2}$ & 1.53 & 14.24 & 5.00 & 34.94 \\
\hline Idling time $(\mathrm{s}) /(\%)$ & 280 & $23.73(24.83)$ & 226 & $12.56(13.56)$ \\
\hline
\end{tabular}

Comparison of the engine speed/power distribution between the NEDC and the WLTP - higher values of power and speed as well as broader distribution are evidenced for the WLTP over its NEDC counterpart, a fact that is expected to affect accordingly the emitted pollutants (Evangelos, 2017).

\section{Simulation}

The Ricardo Ignite software was used to simulate the driving gear. The vehicle model contained the parameters of Škoda Rapid (mechanical five-speed gearbox) and the vehicle "drove through" the defined driving tests - in our case the NEDC and WLTC test, which is prescribed by legislation in force. In the simulation model, the values of a real four-cylinder $1.6 \mathrm{dm}^{3}$ petrol engine with maximum power of $81 \mathrm{~kW}$ at $5800 \mathrm{rpm}$ and maximum torque of $155 \mathrm{Nm}$ at $3800 \mathrm{rpm}$ were used. In the simulation model, the entire driving gear of a vehicle (the parameters of the internal combustion engine - the full load characteristic, the full characteristic of the fuel consumption, the braking torque, the $\mathrm{CO}_{2}$ production - the gearbox, the gear shift strategy, the losses and the individual effectiveness), the driver behavior and the vehicle driving cycle had to be completely defined. The simulation model did not use a cold start for internal combustion engine, which means that the vehicle traveled the whole cycle with a heated engine. The simulation has been done so far for a vehicle with a conventional driving gear system using only an internal combustion engine. In the future it is assumed to use this simulation model for a hybrid driving gear. The simulation results for both homologation cycles are shown in Figure 2.

The total $\mathrm{CO}_{2}$ emissions produced by the vehicle in the NEDC test were $138.38 \mathrm{~g} / \mathrm{km}$, which is in good agreement with the manufacturer's stated value (difference $1.2 \%-140,07 \mathrm{~g} / \mathrm{km}$ ) (Laurin, 2015), the WLTC test was $138.42 \mathrm{~g} / \mathrm{km}$. 

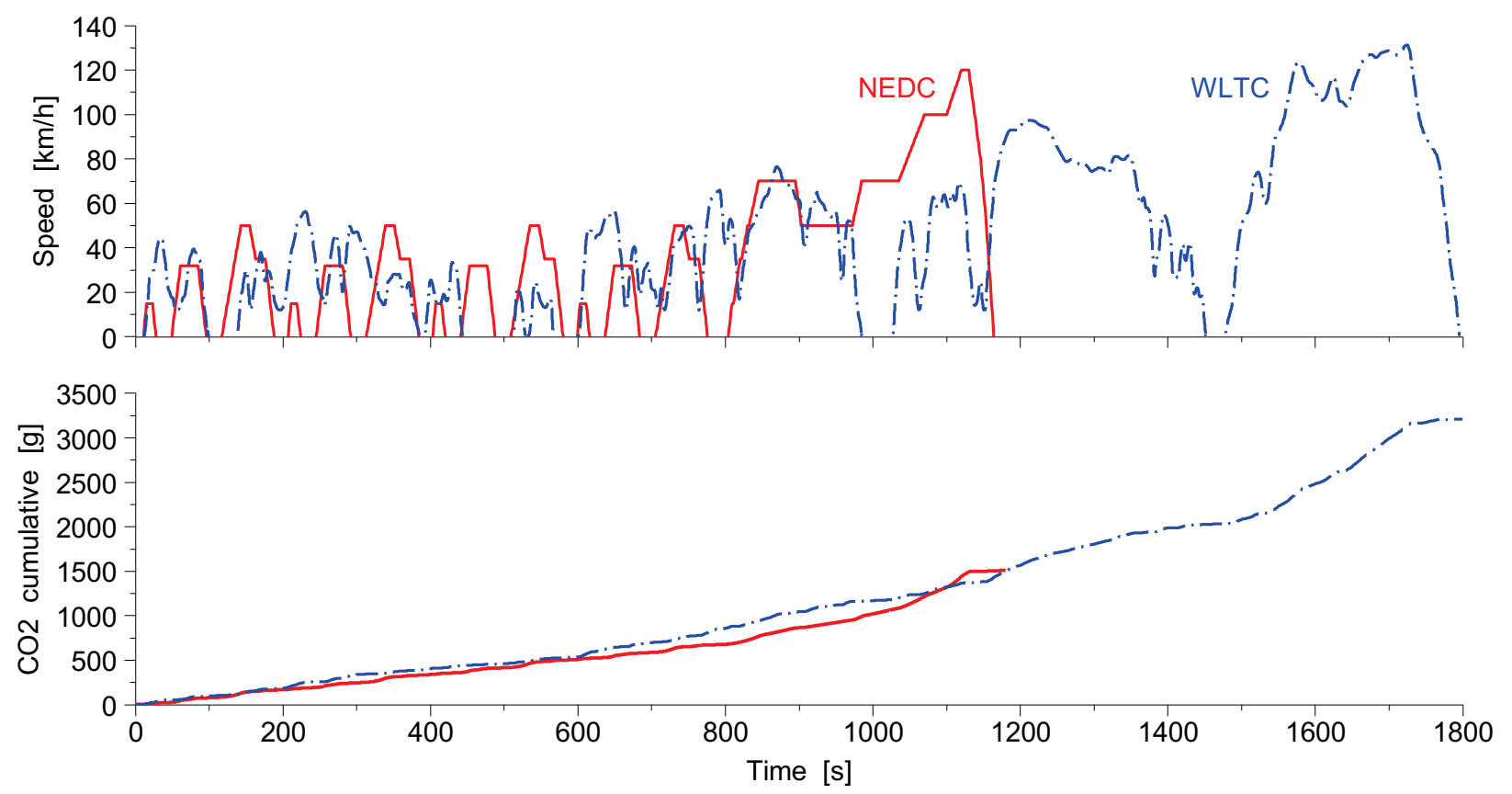

Fig. 2: Simulation Results - illustration of $\mathrm{CO}_{2}$ emissions produced.

In the publication (Mock et al., 2014) both cycles are compared using a quotient. We calculate the quotients of distance-based $\mathrm{CO}_{2}$ emissions in WLTP and NEDC to arrive at the WNQ, the WLTC-NEDC Quotient:

$$
W N Q=\frac{C O_{2} W L T C\left[\frac{\mathrm{g}}{\mathrm{km}}\right]}{C O_{2} N E D C\left[\frac{\mathrm{g}}{\mathrm{km}}\right]} .
$$

In the literature (Mock et al., 2014), many examples of WNQ quotient results can be found in graphs and tables determined by simulation or measurement. The results for example show that it is no longer so useful to use the Start-Stop system (SS system) in the new WLTC emission cycle - for vehicles with an SS system, the VNQ quotient is on average higher by 0.3. The VNQ is higher for diesel engines in most categories of vehicles.

\section{Conclusions}

A simulation model of a passenger vehicle was created to determine the fuel consumption and $\mathrm{CO}_{2}$ emissions production at different driving cycles. It was subsequently verified with the measured emission cycle NEDC, and a very good match was issued. This simulation model can be used to assess the individual adjustments to reduce the vehicle fuel consumption and the emissions, for example optimization of the mass of the vehicle, air resistance, use of tires with reduced rolling resistance, reduction of friction losses in the driving gear, gear shift optimization (use of DSG automatic gearboxes, multiple gears, etc.), combustion engine cooling circuit optimization (faster warm-up after start), combustion engines with fully variable valve train (without throttle), fuel change (e.g. gaseous fuel), or hybrid driving gear. The next picture for example illustrates so-called downsizing. Its principle lies in a significant reduction of the displacement volume of engine and possibly of the number of cylinders. Identical or higher performance parameters are then achieved by supercharging or higher supercharging. In the driving emission cycle the operating mode of the internal combustion engine will be in the area of higher load, which means higher efficiency. In the simulation model we used a supercharged engine with smaller swept volume for the identical vehicle parameters; in both emission cycles the production of $\mathrm{CO}_{2}$ emissions dropped (NEDC - 12.3\%, WLTC -10.7\%) - the operating areas of engines shows Figure 3. 

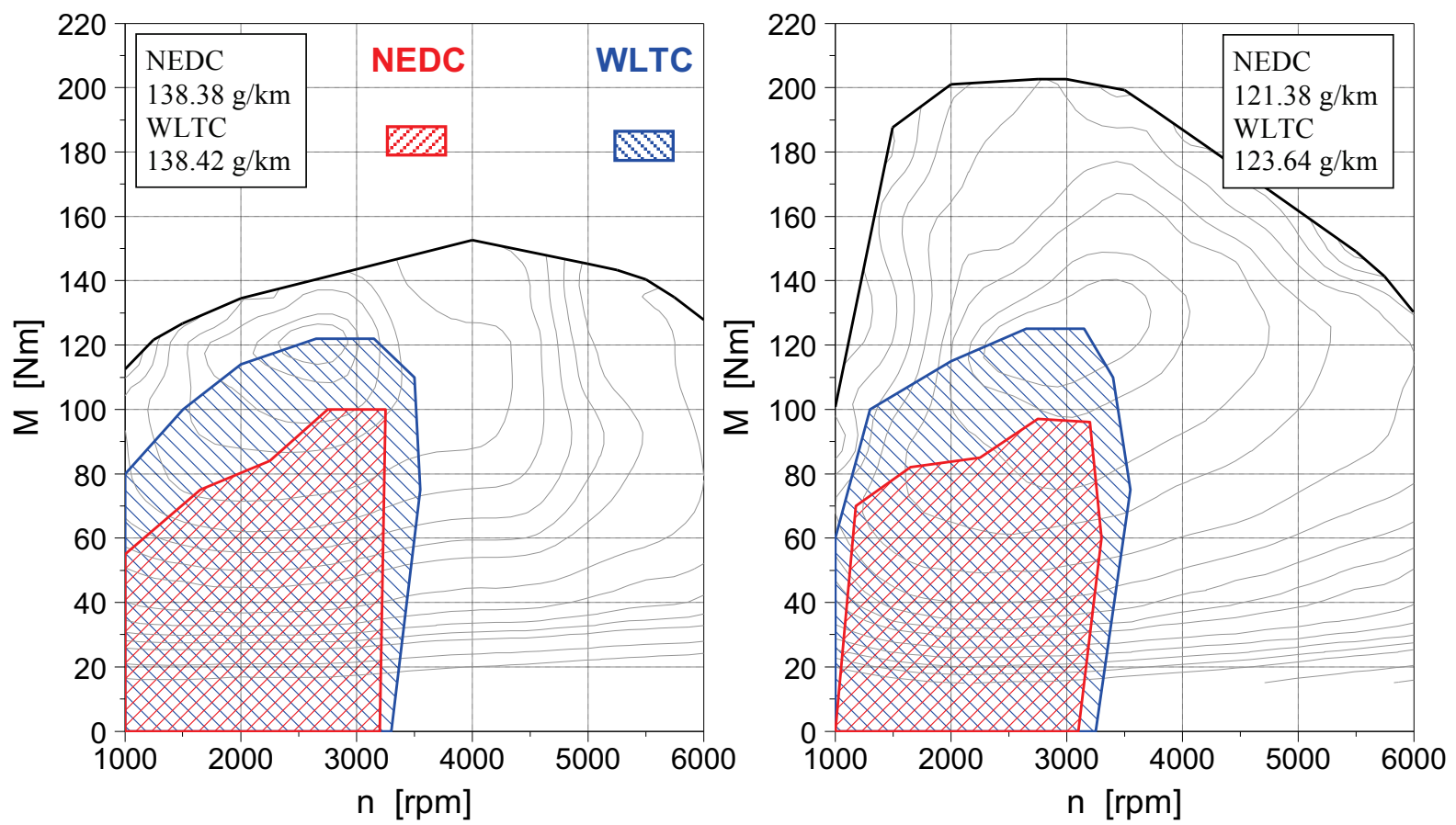

Fig. 3: In the figure on the left there is an example of the use of the operating area for both driving tests on a not-supercharged four-cylinder gasoline engine (1.6 liters), on the right a three-cylinder supercharged 1.0 liter petrol engine with direct injection of gasoline into the cylinder is used for the same vehicle.

Comparison of the engine speed/power distribution between the NEDC and the WLTP - higher values of power and speed as well as broader distribution are evidenced for the WLTP over its NEDC counterpart, a fact that is expected to affect accordingly the emitted pollutants. (Evangelos, 2017).

Of course there are concepts for new drives, from optimized conventional engines to electric drives or fuel cells. All of these are under consideration for trying to reduce $\mathrm{CO}_{2}$ emissions and seek independence of humankind from fossil fuels. For the good of our planet, it is necessary to assess $\mathrm{CO}_{2}$ emissions in a comprehensive way, and therefore to take into consideration the preparation/production of energy/fuel, vehicle production and its later recycling (that is Well-to-Wheel, Well-to-Tank and Tank-toWheel).

\section{Acknowledgement}

This publication was written at the Technical University of Liberec as part of the project 21127 with the support of the Specific University Research Grant, as provided by the Ministry of Education, Youth and Sports of the Czech Republic in the year 2018.

\section{References}

Denner V. (2013) Shaping the Future - Innovations for Efficient Mobility, in: Proc. 34. Internationales Wiener Motorensymposium 2013, pp. 1-17

Evangelos G. G. (2017) Driving and Engine Cycles. Springer International Publishing, Switzerland, , pp. 157-162, 350,374

Kirsten K. (2011) The variable valve train in the debate on downsizing and hybrid drives, in: Proc. 32. Internationales Wiener Motorensymposium 2011, pp. 311-327

Laurin J. (2015) Catalytic reactors, Student text, p. 4, TUL, Liberec (in Czech) http://tkmost.kez.tul.cz/vystupyprojektu/inovace-vyuky-v-oblasti-specializovanych-predmetu/pohonne-jednotky

Mock P., Kühlwein J., Tietge U., Franco V., Bandivadekar A. and German J. (2014) The WLTP: How a new test procedure for cars will affect fuel consumption values in the EU. in: ICCT - the International Council on Clean Transportion.

Schöppe D., Zhang H., Rösel G., Achleitner E., Kapphan F. and Dupont H. (2013) Next Generation Engine Management Systems for Gasoline Direct Injection, in: Proc. 34. Internationales Wiener Motorensymposium 2013, pp. 343-370 